\title{
National Survey of Prevalence of Mental Disorders in Egypt: preliminary survey
}

M. Ghanem, ${ }^{1}$ M. Gadallah, ${ }^{2}$ F.A. Meky, ${ }^{2}$ S. Mourad ${ }^{3}$ and G. El-Kholy ${ }^{1}$

$$
\begin{aligned}
& \text { المسح الوطني لمعدَّلات انتشار الاضطر ابات النفسية في مصر : مسح أولي }
\end{aligned}
$$

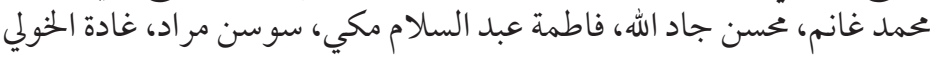

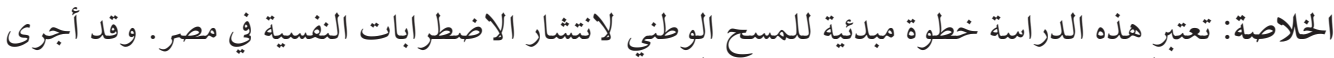

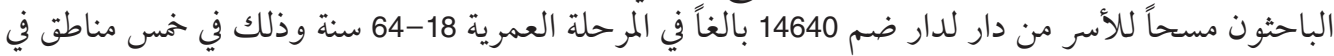

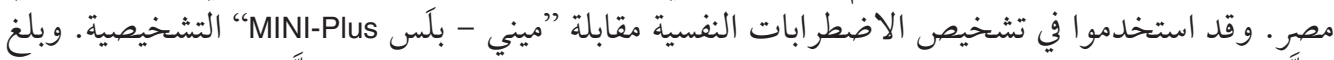

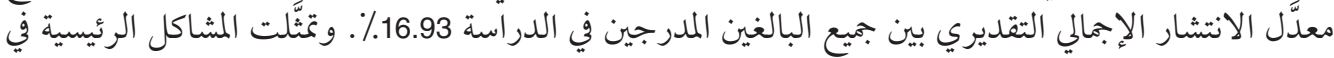

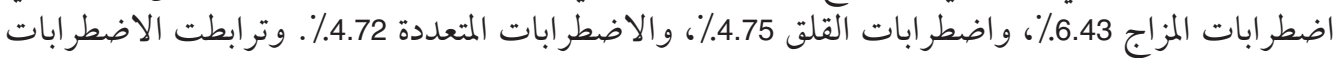

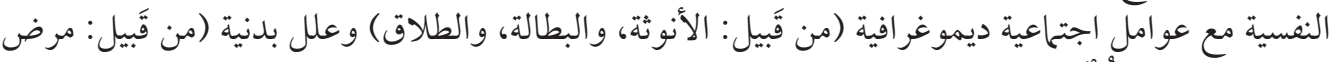

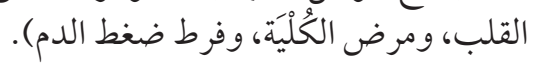

ABSTRACT This study is an initial step for the National Survey of Prevalence of Mental Disorders in Egypt. We conducted a door-to-door household survey of 14640 adults aged 18-64 years in 5 regions in Egypt. Mental disorders were diagnosed using the MINI-Plus diagnostic interview. Overall prevalence was estimated at $16.93 \%$ of the studied adult population. The main problems were mood disorders, $6.43 \%$, anxiety disorders, $4.75 \%$, and multiple disorders, $4.72 \%$. Mental disorders were associated with sociodemographic factors (e.g. being female, being unemployed, being divorced) and physical illness (e.g. heart disease, kidney disease, hypertension).

\section{Enquête nationale sur la prévalence des troubles mentaux en Égypte : étude préliminaire}

RÉSUMÉ Cette étude constitue une première étape de l'enquête nationale sur la prévalence des troubles mentaux en Égypte. Nous avons réalisé une enquête auprès des ménages par porte à porte dans cinq régions d'Égypte et avons interrogé 14640 adultes âgés de 18 à 64 ans. Les troubles mentaux ont été diagnostiqués sur la base de l'interrogatoire MINI-Plus. La prévalence globale a été estimée à $16,93 \%$ de la population adulte étudiée. Les principaux problèmes étaient des troubles de I'humeur $(6,43 \%)$, des troubles anxieux $(4,75 \%)$ et des troubles multiples $(4,72 \%)$. Les troubles mentaux étaient associés à des facteurs sociodémographiques (par exemple le fait d'être une femme, de ne pas avoir de travail et d'être divorcé) et à des maladies physiques (par exemple une cardiopathie, une maladie rénale ou une hypertension).

\footnotetext{
${ }^{1}$ Department of Neuro-Psychiatry; ${ }^{2}$ Department of Community, Environment and Occupational Medicine, Ain Shams University, Cairo, Egypt (Correspondence to F.A. Meky: fammeky@yahoo.co.uk).

${ }^{3}$ Abbassia Mental Hospital, Ministry of Health, Cairo, Egypt.

Received: 24/01/06; accepted: 27/06/06
}

المجلة الصحية لشرق المتوسط، منظمة الصحة العالمية، المجلد الخامس عشر، العدد (، 9 +. 


\section{Introduction}

The world is suffering from an increasing burden of mental disorders and a widening treatment gap: about 450 million people suffer from a mental or behavioural disorder, yet only a small minority receives even the most basic treatment. Mental disorder cases are likely to increase due to ageing of the population and deterioration in infrastructure and public health services [1]. Mental disorders are known to have a greater negative effect on role functioning than many serious chronic physical illnesses [2]. In the original global estimates drawn up for 1990, mental and neurological disorders accounted for $10.5 \%$ (projected to increase to $15 \%$ in the year 2020 [3]) of the total disabilityadjusted life years (DALYs) lost due to all diseases and injuries. It ranked in the top 20 leading causes of DALYs for all ages and in the top 6 in the age group 15-44 years.

Although surveys of mental disorders have been carried out since the end of World War II, little is known about the extent or severity of untreated mental disorders, especially in developing countries like Egypt. Health care delivery in Egypt still faces many problems. Both facilities and staff tend to be unevenly distributed, clustering mainly in urban areas, such as Cairo and Alexandria. The total number of available beds for psychiatric cases is inadequate: less than 10000 beds, around 13 per 100000 population. The number of professionals specialized in mental health is far below international standards. The main obstacle facing the services, however, is that they are hospital-based rather than community-based [4].

Lack of information about mental health statistics is one of the most prominent problems in Arab countries. A community study in Dubai estimated the prevalence of mental disorders to be $18.9 \%$ in 2001 [5]. In a 1988 survey of a community sample from an urban and rural population in Egypt, prevalence of depression was $15.3 \%$ [6].

In Egypt, there is a scarcity of community surveys in the field of psychiatry. We need such information as a base for future mental health planning, development, training and incorporation of mental health in primary health care. This study aimed to provide an accurate estimate of the prevalence of common mental disorders in 5 different regions in Egypt, and to investigate sociodemographic factors associated with these disorders as part of a national survey. This project aims to shed light on the true epidemiological status of psychiatric disorders in the country. The second phase will be to cover governorates which have different socioeconomic conditions, notably those in Upper Egypt.

\section{Methods}

According to the population census of 2003, for each selected region, a proportionate sample was determined as follows: Alexandria 3750, Giza 3500, Qaliubia 3250, Fayoum 3000 and Ismailia 1500. From each region, 10 sites were selected to represent different socioeconomic levels taking into account cultural and geographic factors. Each site was classified into 4 areas (North, South, East, and West). In each area, the health field team decided on a landmark as the starting point; house selection started at the first house beside the landmark and then moved in a clockwise direction until the required sample size from that area was achieved. The representative sample comprised all adult residents aged 18-64 years in selected households in 5 regions in Egypt. We selected only those who had lived for $\geq 6$ months in the house. We excluded people who were not normally resident such 
as military personnel, prisoners and those receiving long-term inpatient care.

In preparation for the survey, a World Health Organization expert visited the General Secretariat of Mental Health for 10 days in October 2002 to carry out the situational analysis of mental health disorders and their determinants and to design the survey. The leaders of the research team held several meetings in each governorate to explain the aim of study, choose the research staff, facilitate the implementation of work, and to discuss the preparation of the training programmes implemented before the fieldwork started. Before starting the fieldwork all interviewers and supervisors attended a standard training programme conducted by Egyptian university consultants over 3 full days. The curriculum included interviewing techniques, explanation of the aims of the study, procedures, consent forms, administration of tools and data entry as well as practical training on a sample of a few cases.

A pilot study was carried out on 150 people in Alexandria and Fayoum after the training programme to test the application of the instruments and logistics with the interviewers and to identify any problems. Patient compliance was also ascertained. A monthly meeting was also held and individualized training was given to fieldworkers on how to increase patient compliance.

The field study was done during the period mid-August-end of November 2003. Recruitment took place under the supervision of the local health district. Participants were contacted either by telephone or via a home visit by a primary health care nurse, after which a fieldworker visited the house. If nobody was present, the next house was selected. On initial contact, the fieldworker introduced him/herself to the participants and explained the purpose of the survey. All eligible residents in the selected household were approached and asked to participate. If anyone was absent at the time of the first visit, the house was revisited at an arranged time when he/she was available. Participants had the opportunity to ask questions, and were asked to give their consent.

\section{Instruments}

Trained nurses visited the homes of participants and completed a sociodemographic questionnaire designed to assess the risk factors for mental disorder. The questionnaire included data about age, sex, education, crowding index, employment, residence, smoking, alcohol intake, religion and present or past history of chronic physical illness. A fieldworker administered the Arabic version of the MINI-Plus instrument for diagnosing mental disorders [7]. This was designed as a brief structured interview for the major Axis I psychiatric disorders in DSM-IV and ICD-10. Validation and reliability studies have been done comparing the MINI-Plus to the SCID-P and the CIDI, the 2 most widely used instruments. The MINI-Plus has acceptably high validation and reliability scores, but can be administered in a short period of time [mean 18.7 (standard deviation 11.6) minutes] compared to the 1-2 hours required for the other 2 instruments [8]. All sections of the MINI-Plus were used except those relating to eating disorders, attention-deficit/hyperactivity disorder, major depressive episode with melancholic features, suicide and antisocial personality disorder.

Within 2 weeks, $5 \%$ of all those we interviewed were revisited to check for accuracy of diagnosis as a form of quality control assessment. This was carried out by 60 trained primary health care doctors working 3 days per week interviewing 4 people/day. The interviewers made the diagnosis of mental disorders. Local and central supervisors reviewed all questionnaires before data

المجلة الصحية لشرق المتوسط، منظمة الصحة العالمية، المجلد الخامس عشر، العدد (، 9 ·. 
entry; missing data were checked with the corresponding field supervisor. Data entry and analysis were done by trained personnel under the supervision of the senior epidemiologist of the programme.

\section{Statistical analysis}

We used SPSS for bivariate analysis. Epicalc 2000 was used to calculate the confidence interval (CI) of the prevalence of different types of mental disorder. Logistic regression analyses were used for estimation of the association of each socioeconomic factor or chronic illness with mental disorder, after adjustment for age. Similar analyses were repeated after stratification of subjects by sex. Age-adjusted odds ratios (ORs) with 95\% CI were reported. We estimated the association of each chronic disease with the outcome, adjusting for all socioeconomic variables identified in the previous step.

\section{Results}

The study sample included 15000 participants: 360 were excluded from the analyses as they were not within the predetermined age range, had an unidentified diagnosis or there were errors in data entry.

The overall prevalence of mental disorders in the surveyed sample was $16.93 \%$ (95\% CI: $16.35 \%-17.57 \%$ ). As group entities, the 3 most common disorders in the surveyed sample were mood disorders $(6.43 \%)$, anxiety disorders $(4.75 \%)$ and multiple disorders $(4.72 \%)$ (Table 1$)$. The most common disorders detected in the sample were major depressive disorder $(2.70 \%)$ and premenstrual dysphoric disorder $(2.52 \%)$. The least common were alcohol dependence/abuse (only 5 cases) and adjustment disorder (only 4 cases).

Women had a significantly higher odds of having a mental disorder $(\mathrm{OR}=2.24$;
$P<0.001)$. Odds were also significantly higher among those living in Ismailia, Giza and Fayoum compared to those living in Alexandria (Table 2). Other significant risk factors for mental disorder included occupation (housewife, unemployed), marital status (widowed, divorced). Odds of mental disorder did not differ by residence, but was significantly lower among those having secondary or higher education. In addition, having $\leq 3$ children and being a current smoker were protective factors.

Crowding index $>3$ was the only significant socioeconomic factor associated with mental disorder $(\mathrm{OR}=1.26$; $\mathrm{CI}$ : 1.13-1.41; $P<0.001)$. Other factors such as having a car or living in a home connected to the water and sewerage systems were not associated with having a mental disorder.

Table 3 shows the association of sociodemographic risk factors with mental disorders in general stratified by sex. Among men, not being professional significantly increased the OR. In addition, the odds ratio of having a mental disorder was significantly dependent on marital status: the ORs were 4.79, 3.25, and 1.32 for divorced, widowed and single respectively compared to married men. Having smoked cigarettes (current or ex-smoker) increased the risk for mental disorders $54 \%$ to $58 \%$ compared to non-smokers. Economic variables such as crowding index were significantly associated with increased risk of mental disorders. However, having education (secondary education or university degree) and having children were protective.

Similarly, among women marital status (divorced, widowed compared to married) was a significant risk factor and having a university degree was protective. Contrary to men, occupation, having children, having smoked cigarettes and economic variables such as crowding index $<3$ were not associated with mental disorders. 
Table 1 Prevalence of mental disorders in Egypt $(n=14640)$

\begin{tabular}{lccc}
\hline Type of disorder & Frequency & Rate (\%) & 95\% Cl \\
\hline Mood & 942 & 6.43 & $6.04-6.84$ \\
Major depressive disorder & 395 & 2.70 & $2.45-2.98$ \\
Dysthymia & 151 & 1.03 & $0.88-1.21$ \\
Hypomanic episode & 27 & 0.18 & $0.12-0.27$ \\
Premenstrual dysphoric disorder & 369 & 2.52 & $2.77-2.79$ \\
Anxiety & 694 & 4.75 & $4.40-5.10$ \\
Panic & 100 & 0.68 & $0.56-0.83$ \\
Agoraphobia & 73 & 0.50 & $0.39-0.63$ \\
Social phobia & 33 & 0.23 & $0.16-0.33$ \\
Specific phobia & 197 & 1.35 & $1.17-1.55$ \\
Obsessive-compulsive & 99 & 0.68 & $0.56-0.83$ \\
Post traumatic stress & 16 & 0.11 & $0.07-0.18$ \\
Generalized anxiety & 133 & 0.91 & $0.77-1.08$ \\
Mixed anxiety depressive & 43 & 0.29 & $0.21-0.40$ \\
Somatoform & 97 & 0.67 & $0.54-0.81$ \\
Somatization & 20 & 0.14 & $0.09-0.22$ \\
Hypochondriasis & 45 & 0.31 & $0.23-0.42$ \\
Body dysmorphic & 21 & 0.14 & $0.09-0.22$ \\
Pain & 11 & 0.08 & $0.04-0.15$ \\
Psychotic & 28 & 0.19 & $0.13-0.28$ \\
Alcohol dependence/abuse & 5 & 0.03 & $0.01-0.08$ \\
Drug dependence/abuse & 19 & 0.13 & $0.08-0.21$ \\
Adjustment & 4 & 0.03 & $0.01-0.08$ \\
Multiple & & 4.72 & $4.38-5.08$ \\
\hline Cl & & &
\end{tabular}

$\mathrm{Cl}=$ confidence interval.

The association of sociodemographic risk factors with the most prevalent mental disorders such mood disorders and anxiety disorders stratified by sex was computed (data not shown): only occupation (skilled, retired or unemployed compared to professional) was associated with increased odds of mood disorder $(\mathrm{OR}=2.07,2.02$ and 5.09 respectively).

The risk for mental disorder was significantly higher in those having hypertension $(\mathrm{OR}=1.66)$, heart disease $(\mathrm{OR}=2.06)$, diabetes mellitus $(\mathrm{OR}=1.25)$ and kidney disease $(\mathrm{OR}=1.95)$ (Table 2$)$. Using logistic regression analysis, the association be- tween chronic disease and mental disorders remained significant even after adjustment for sociodemographic variables such as sex, education and marital status.

\section{Discussion}

The strengths of this study were using a valid, reliable and brief structured psychiatry interview questionnaire (MINI-Plus) administered to a large representative sample, covering a wide age range and including both urban and rural residents in different regions in Egypt. Trained physicians, and 
Table 2 Association of sociodemographic characteristics and chronic disease with mental disorder in a sample of 14640 participants from 5 areas in Egypt, 2003

\begin{tabular}{|c|c|c|c|c|}
\hline \multirow[t]{2}{*}{ Variable $^{a}$} & \multirow{2}{*}{$\begin{array}{l}\text { Total } \\
\text { No. }\end{array}$} & \multicolumn{2}{|c|}{ Having mental disorder } & \multirow{2}{*}{$\begin{array}{l}\text { Age adjusted OR } \\
(95 \% \mathrm{Cl})\end{array}$} \\
\hline & & No. & $\%$ & \\
\hline \multicolumn{5}{|l|}{ Sex } \\
\hline Male & 5781 & 613 & 10.6 & 1 \\
\hline Female & 8849 & 1866 & 21.1 & $2.24(2.03-2.47)^{\star \star *}$ \\
\hline \multicolumn{5}{|l|}{ Governorate } \\
\hline Alexandria & 3700 & 408 & 11.0 & 1 \\
\hline Ismailia & 1479 & 193 & 13.0 & $1.21(1.01-1.45)^{\star}$ \\
\hline Qualiobia & 3411 & 795 & 23.3 & $1.05(0.90-1.22)$ \\
\hline Giza & 3151 & 363 & 11.5 & $2.44(2.14-2.78)^{\star \star \star}$ \\
\hline Fayoum & 2899 & 721 & 24.9 & $2.66(2.32-3.03)^{\star \star *}$ \\
\hline \multicolumn{5}{|l|}{ Residence } \\
\hline Urban & 7671 & 1268 & 16.5 & 1 \\
\hline Rural & 6969 & 1212 & 17.4 & $1.02(0.99-1.11)$ \\
\hline \multicolumn{5}{|l|}{ Education } \\
\hline Below secondary & 8339 & 1561 & 18.7 & 1 \\
\hline Secondary & 4297 & 665 & 15.5 & $0.74(0.67-0.82)^{\star \star \star}$ \\
\hline University & 1879 & 237 & 12.6 & $0.59(0.51-0.68)^{\star \star *}$ \\
\hline \multicolumn{5}{|l|}{ Occupation } \\
\hline Professional & 2502 & 288 & 11.5 & 1 \\
\hline Housewife & 6738 & 1432 & 21.3 & $2.07(1.80-2.37)^{\star * *}$ \\
\hline Skilled & 2397 & 298 & 12.4 & $1.07(0.90-1.27)$ \\
\hline Unskilled & 432 & 55 & 12.7 & $1.02(0.82-1.27)$ \\
\hline Retired & 878 & 187 & 21.3 & $1.21(0.88-1.67)$ \\
\hline Unemployed & 1120 & 131 & 11.7 & $1.10(1.62-2.45)^{\star * *}$ \\
\hline \multicolumn{5}{|l|}{ Marital status } \\
\hline Married & 10943 & 1833 & 16.8 & 1 \\
\hline Divorced & 163 & 56 & 34.4 & $2.59(1.87-3.60)^{\star \star \star}$ \\
\hline Widowed & 687 & 157 & 22.9 & $1.75(1.44-2.13)^{\star \star \star}$ \\
\hline Single & 2642 & 411 & 15.6 & $0.76(0.67-0.87)^{\star \star \star}$ \\
\hline \multicolumn{5}{|l|}{ No. of children ${ }^{b}$} \\
\hline None & 700 & 141 & 20.1 & 1 \\
\hline $1-3$ & 6444 & 1031 & 16.0 & $0.79(0.65-0.97)^{*}$ \\
\hline$>3$ & 7496 & 1308 & 17.4 & $0.73(0.73-1.09)$ \\
\hline \multicolumn{5}{|l|}{ Smoking } \\
\hline Non-smoker & 11459 & 2071 & 18.1 & 1 \\
\hline Current smoker & 2512 & 322 & 12.8 & $0.68(0.60-0.77)^{\star \star \star}$ \\
\hline Ex-smoker & 289 & 39 & 13.5 & $0.73(0.52-1.02)$ \\
\hline \multicolumn{5}{|l|}{ Having hypertension } \\
\hline No & 11455 & 2247 & 19.6 & 1 \\
\hline Yes & 919 & 262 & 28.5 & $1.66(1.43-1.95)^{\star \star \star}$ \\
\hline
\end{tabular}




\begin{tabular}{|c|c|c|c|c|}
\hline \multirow[t]{2}{*}{ Variable $^{a}$} & \multirow{2}{*}{$\begin{array}{l}\text { Total } \\
\text { No. }\end{array}$} & \multicolumn{2}{|c|}{ Having mental disorder } & \multirow{2}{*}{$\begin{array}{c}\text { Age adjusted OR } \\
(95 \% \mathrm{Cl})\end{array}$} \\
\hline & & No. & $\%$ & \\
\hline \multicolumn{5}{|c|}{ Having diabetes mellitus } \\
\hline No & 11708 & 2355 & 20.1 & 1 \\
\hline Yes & 664 & 155 & 23.3 & $1.25(1.06-1.55)^{\star \star}$ \\
\hline \multicolumn{5}{|c|}{ Having liver disease } \\
\hline No & 12161 & 2457 & 20.2 & 1 \\
\hline Yes & 211 & 50 & 23.7 & $1.25(0.91-1.70)^{\star \star \star *}$ \\
\hline \multicolumn{5}{|c|}{ Having heart disease } \\
\hline No & 12163 & 2431 & 19.9 & 1 \\
\hline Yes & 207 & 79 & 38.2 & $2.06(1.61-2.74)$ \\
\hline \multicolumn{5}{|c|}{ Having cancer } \\
\hline No & 12352 & 2503 & 20.3 & 1 \\
\hline Yes & 17 & 7 & 41.2 & $2.14(0.89-5.17)$ \\
\hline \multicolumn{5}{|c|}{ Having kidney disease } \\
\hline No & 12175 & 2436 & 20.4 & 1 \\
\hline Yes & 195 & 73 & 37.4 & $1.95(1.46-2.53)^{\star \star}$ \\
\hline \multicolumn{5}{|c|}{ Having schistosomiasis } \\
\hline No & 12249 & 2483 & 20.3 & 1 \\
\hline Yes & 122 & 27 & 22.1 & $1.10(0.72-1.67)$ \\
\hline
\end{tabular}

${ }^{a}$ Totals may vary owing to missing data.

${ }^{b}$ Question only asked of married, widowed or divorced participants.

${ }^{\star} \mathrm{P}<0.05 ;{ }^{* *} \mathrm{P}<0.01 ;{ }^{* * *} \mathrm{P}<0.001$.

$\mathrm{OR}=$ odds ratio; $\mathrm{Cl}=$ confidence interval.

primary health care nurses, closely supervised by psychiatrists, conducted the study.

Nevertheless, this was a cross-sectional study which did not involve children under 18 years, those over 64 years, the homeless, hospitalized/institutionalized persons or prisoners. It would, therefore, be imprudent to generalize our results to the whole country.

Overall, the prevalence of mental disorders varies widely among different countries; the rate has been found to be lowest in China and highest in the United States of America (USA) [9]. In the present study, the overall prevalence $(16.95 \%)$ was similar to that in other Arab countries such as Dubai
(18.9\%) [5] and Lebanon (16.9\%) [9]. It was also comparable to some European countries such as France (18.4\%) and the Netherlands (14.9\%) [9].

Mood and anxiety disorders were the commonest disorders reported in this study. Studies from areas such as the USA, Europe, Lebanon and Japan revealed the same findings [9]. Alcohol and drug dependence/ abuse were the least prevalent in this study, but these results could be inaccurate: they may reflect the non-reliability of substance abuse questions or perhaps the lack of privacy during the interview forced participants to conceal this information, especially in the presence of family members. 


\begin{tabular}{|c|c|c|c|c|}
\hline \multirow[t]{2}{*}{ Variable } & \multicolumn{2}{|c|}{ Men $(n=5781)$} & \multicolumn{2}{|c|}{ Women $(n=8849)$} \\
\hline & $\%$ & OR $(95 \% \mathrm{Cl})$ & $\%$ & OR $(95 \% \mathrm{Cl})$ \\
\hline \multicolumn{5}{|l|}{ Residence } \\
\hline Urban & 10.5 & 1 & 20.7 & 1 \\
\hline Rural & 10.7 & $1.02(0.87-1.21)$ & 21.5 & $1.03(0.93-1.15)$ \\
\hline \multicolumn{5}{|l|}{ Education } \\
\hline Below secondary & 12.7 & 1 & 21.7 & 1 \\
\hline Secondary & 8.9 & $0.66(0.54-0.81)^{\star \star \star}$ & 20.9 & $0.89(0.78-1.01)$ \\
\hline University & 8.2 & $0.61(0.74-0.78)^{\star \star \star}$ & 18.0 & $0.75(0.62-0.90)^{* *}$ \\
\hline \multicolumn{5}{|l|}{ Occupation } \\
\hline Professional & 7.9 & 1 & 19.9 & 1 \\
\hline Housewife & - & - & 21.3 & $1.09(0.90-1.31)$ \\
\hline Skilled & 10.9 & $1.46(1.16-1.83)^{\star \star}$ & 19.2 & $0.90(0.67-1.22)$ \\
\hline Unskilled & 10.5 & $1.37(1.05-1.79)^{*}$ & 20.6 & $1.05(0.67-1.65)$ \\
\hline Retired & 12.6 & $1.52(1.06-2.20)^{\star \star \star}$ & 16.7 & $0.88(0.25-3.09)$ \\
\hline Unemployed & 16.9 & $2.49(1.81-3.43)^{\star}$ & 25.2 & $1.30(0.67-1.65)$ \\
\hline \multicolumn{5}{|l|}{ Marital status } \\
\hline Married & 10.1 & 1 & 20.8 & 1 \\
\hline Divorced & 34.5 & $4.79(2.21-10.38)^{\star \star *}$ & 34.1 & $1.10(1.39-2.88)^{\star \star *}$ \\
\hline Widowed & 28.6 & $3.25(1.54-6.68)^{\star \star}$ & 22.5 & $1.29(1.04-1.58)^{\star}$ \\
\hline Single & 11.4 & $1.32(1.03-1.69)^{\star}$ & 21.1 & $0.90(0.76-1.06)$ \\
\hline \multicolumn{5}{|l|}{ No. of children } \\
\hline None & 18.0 & 1 & 22.5 & 1 \\
\hline $1-3$ & 8.9 & $0.40(0.29-0.55)^{\star \star \star}$ & 20.1 & $0.92(0.70-1.20)$ \\
\hline$>3$ & 11.0 & $0.37(0.37-0.69)^{\star \star \star}$ & 21.9 & $1.06(0.81-1.39)$ \\
\hline \multicolumn{5}{|l|}{ Smoking } \\
\hline Non-smoker & 8.6 & 1 & 21.4 & 1 \\
\hline Current smoker & 12.7 & $1.54(1.29-1.84)^{* \star \star}$ & 18.3 & $0.85(0.46-1.35)$ \\
\hline Ex-smoker & 12.9 & $1.58(1.08-2.30)^{\star}$ & 30.0 & $1.60(0.41-6.20)$ \\
\hline
\end{tabular}

${ }^{*} \mathrm{P}<0.05 ;{ }^{* *} \mathrm{P}<0.01 ;{ }^{* * *} \mathrm{P}<0.001$.

$\mathrm{OR}=$ age adjusted odds ratio; $\mathrm{Cl}=$ confidence interval.

In our study, point prevalence rate was $4.72 \%$ for multiple mental disorders, a rate similar to that in Mexico (5.4\%) and Turkey (4.4\%), but lower than in the USA $(27.4 \%)$ and Canada (16.3\%) [9]. Psychotic disorders represent only $0.19 \%$ in our study, which is less than what has been reported from Dubai (0.7\%) [5]. The low figure may be the result of cultural denial of psychosis because of the stigma related to that disorder. There are also probably psychotics among those not included in our study, such as homeless people, prisoners and those in mental hospitals.

The risk of mental disorder among women was over 2 times higher than among men, consistent with many reports from both developing and developed countries 
[10-13]. Apart from the possible biological factors which may explain the differences in all societies, in many developing countries women bear the brunt of the adversities associated with poverty: less access to education, physical abuse from husbands, forced marriages, fewer job opportunities and, in some societies, limitation of participation in activities outside the house [14].

The increased risk of mental disorders in Fayoum and Ismailia compared to Alexandria may be a result of the poorer health services, which may be reflected in the greater numbers of undiscovered and/or untreated cases in these regions. Differences in lifestyle and ability to tolerate stress may also result in increased risk of mental disorders in some regions. Despite living in a big city, Giza residents may have a higher risk for mental disorders for a number of reasons, such as wider geographical distribution, relatively fewer mental health specialists and the absence of tertiary care services, which are provided in Alexandria at Mamoora hospital.

In developing countries, the relationship between urban/rural residence and the prevalence of mental disorders is inconsistent. An epidemiological study in Pakistan found higher prevalence rates of mental disorders in the rural populations [15]. Also, an early study in Egypt showed that depressive disorders were more prevalent in rural residents [6]. In contrast, in Latin America lower rates have been found in rural villages than in urban areas [16]. However, in our study and in a similar study in the Islamic Republic of Iran [17], no differences were found between urban and rural areas. In our country, many rural residents migrate to urban areas and this may create 2 matching communities with the same socioeconomic standards; as a consequence the urban-rural differences found by others may be masked. Both rural and urban residents have specific problems, however, and this may also contribute towards masking the differences. For instance, in urban areas, overcrowding, polluted environment and high levels of violence may affect the rates of mental disorder. Rural residents may face problems such as lack of proper infrastructure and low socioeconomic standards.

Most studies from both developed and developing countries have found that socially disadvantaged groups (illiterate, unemployed) and those who had previously been married had a much higher prevalence of common mental disorders $[1,18,19]$. Similarly in our study, marital status (divorced or widowed), poor education and unemployment all played a significant role. We suggest further analysis of these risk factors will contribute towards primary prevention of mental illness in our culture.

Risk factors for mental disorders were similar for both men and women with the exception of occupation and smoking: these increased the risk of mental disorder in men. Our failure to find an association between mental disorder and occupation may have been because the majority of the women in this study were housewives. Although the prevalence of mental disorders was higher in non-smokers than smokers, most of the non-smokers were females, in whom the prevalence of mental disorder was greater. In support of this, analysis of the association of smoking with mental disorder by sex strata showed that among males, smoking (current or previous smokers) increased the risk of mental disorder. We did not find the same relationship among females. Other studies have shown that depression, and anxiety were strongly positively associated with smoking $[20,21]$.

Among women, sociodemographic factors such as education and marital status played a role in increasing the risk of mental disorders.

المجلة الصحية لشرق المتوسط، منظمة الصحة العالمية، المجلد الخامس عشر، العدد (،9.ب. 
Chronic illness and poor physical health have been shown to increase the risk of mental disorder [22]. Hypertension, heart disease, diabetes mellitus and kidney disease were all associated with an increased risk of mental disorder in our study. Prevalence rates of diabetes, liver diseases, lower back pain and pulmonary conditions were higher in patients with bipolar disorder than in a national cohort [23]. Moreover, mortality was higher in patients with co-morbidity of depression and chronic kidney disease compared with those with depression and no, or less severe, disease [24]. Sokal et al. reported that persons with serious mental illness who are in care were more likely to have co-morbid medical conditions than persons in the general population, and the odds of diabetes, lung disease, and liver problems were particularly elevated [25]. The co-morbidity of anxiety and physical illness such as cardiac disorders, hypertension, gastrointestinal problems, genitourinary difficulties and migraine has been reported in prior studies [26].
From this study, it is clear that mental disorders are highly prevalent in our country, with noticeable discrepancies between governorates. We recommend further studies to investigate the reasons for these discrepancies.

\section{Acknowledgements}

The World Health Organization in collaboration with the General Secretariat of Mental Health sponsors the National Survey of Mental Health in Egypt. Administrative support was received from the foreign health relations sector of the Ministry of Health and Population, and the undersecretary of health of the selected governorates.

We would like to thank the following people for their valuable contributions during this survey: David Sheehan, Ahmed Mohit, Srinivasa Murthy and Richard Gater. Many thanks go to participants, fieldworkers, staff and everyone who took part in this work.

\section{References}

1. Cross-national comparisons of the prevalence and correlates of mental disorders. WHO International consortium in psychiatric epidemiology. Bulletin of the World Health Organization, 2000, 78(4):413-26.

2. Kessler RC, Frank RG. The impact of psychiatric disorders on work loss days. Psychological medicine, 1997, 27:861-73.

3. Murray C, Lopez A. The global burden of disease: a comprehensive assessment of mortality and disability from diseases, injuries and risk factors in 1990 and projected to 2020. Cambridge, Massachusetts, Harvard School of Public Health on behalf of World Health Organization and World Bank, 1996 (Global Burden of Disease and Injury Series, vol. I).
4. Ghanem M. Psychiatric services and activities in the Ministry of Health and Population. Journal of the Egyptian Psychiatric Association, 2004, 23(2):16-9.

5. Abou-Saleh MT, Ghubash R, Daradkeh TK. Al Ain community psychiatric survey. I: Prevalence and socio-demographic correlates. Social psychiatry \& psychiatric epidemiology, 2001, 36(1):20-8.

6. Okasha A et al. Prevalence of depressive disorders in a sample of rural and urban Egyptian communities. Egyptian journal of psychiatry, 1988, 11:167-81.

7. Ghanem M et al. Development and validation of the Arabic version of the mini international neuropsychiatry interview 
(MINI). Paper presented at the Annual International Conference of The Egyptian Psychiatric Association, Cairo, 24-26 March, 1999.

8. Sheehan DV et al. The Mini International Neuropsychiatry Interview (MINI): the development and validation of a structured diagnostic psychiatric interview. Journal of clinical psychiatry, 1998, 59(Suppl. 20):22-33.

9. WHO World Mental Health Consortium. Prevalence, severity, and unmet need for treatment of mental disorders in the World Health Organization World Mental Health Surveys. Journal of the American Medical Association, 2004, 291(21):2581-90.

10. Alem A et al. The prevalence and sociodemographic correlates of mental distress in Butajira, Ethiopia. Acta psychiatrica scandinavica, 1999, 397(Suppl.):48-55.

11. Kebede D, Alem A, Rashid E. The prevalence and socio-demographic correlates of mental distress in Addis Ababa, Ethiopia. Acta psychiatrica scandinavica, 1999, 397(Suppl.):5-10.

12. Lepine JP et al. Prevalence and comorbidity of psychiatric disorders in the French general population. Encephale, 2005, 31(2):182-94.

13. Lim $L$ et al. Generalised anxiety disorder in Singapore: prevalence, co-morbidity and risk factors in a multi-ethnic population. Social psychiatry \& psychiatric epidemiology, 2005, 40:972-9.

14. Patel V, Kleinman A. Poverty and common mental disorders in developing countries. Bulletin of the World Health Organization, 2003, 81(8):609-18.

15. Mumford DB et al. Stress and psychiatric disorder in urban Rawalpindi. A community survey. British journal of psychiatry, 2000, 177:557-62.

16. Canino GJ et al. The prevalence of specific psychiatric disorders in Puerto Rico. Archives of general psychiatry, 1987, 44(8):727-5.
17. Noorbala AA et al. Mental health survey of the adult population in Iran. British journal of psychiatry, 2004, 184:70-3.

18. Araya $\mathrm{R}$ et al. Common mental disorders in Santiago, Chile: prevalence and sociodemographic correlates. British journal of psychiatry, 2001, 178:228-33.

19. Noorbala A et al. Mental health survey of the adult population in Iran. British journal of psychiatry, 2004, 184:70-3.

20. Averina $M$ et al. Social and lifestyle determinants of depression, anxiety, sleeping disorders and self-evaluated quality of life in Russia-a population-based study in Arkhangelsk. Social psychiatry \& psychiatric epidemiology, 2005, 40(7):511-8.

21. Daniel $\mathrm{J}$ et al. Mental health in the United States: health riskbehaviorsand conditions among persons with depression-New Mexico, 2003. Morbidity and mortality weekly report, 2005, 54(39):989-91.

22. Verhaak PF et al. Chronic disease and mental disorder. Social science \& medicine, 2005, 60(4):789-97.

23. Kilbourne AM et al. Burden of general medical conditions among individuals with bipolar disorder. Bipolar disorders, 2004, 6(5):368-73.

24. Hedayati SS et al. The association between depression and chronic kidney disease and mortality among patients hospitalized with congestive heart failure. American journal of kidney diseases, 2004, 44(2):207-15.

25. Sokal $\mathrm{J}$ et al. Comorbidity of medical illnesses among adults with serious mental illness who are receiving community psychiatric services. Journal of nervous and mental disease, 2004, 192(6):421-7.

26. Harter MC, Conway KP, Merikangas KR. Associations between anxiety disorders and physical illness. European archives of psychiatry and clinical neuroscience, 2003, 253(6):313-20. 